\title{
Book Review - The Publish or Perish Book: Your Guide to Effective and Responsible Citation Analysis
}

Author: Harzing, A-W. (2010-11)

Melbourne, Australia: Tarma Software Research Pty Ltd. ISBN: 978-1-60752-120-4

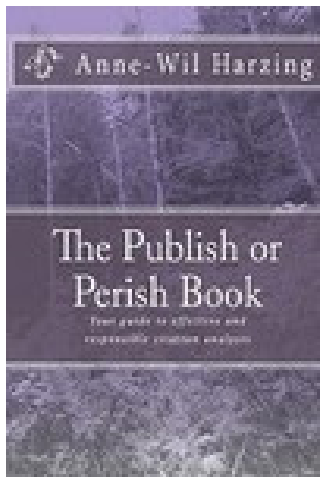

Reviewer: Michael Barbour, Wayne State University, USA

Regular readers of the International Review of Research in Open and Distance Learning (IRRODL) will be familiar with the issues facing the field of distance education, the high number of online and open access journals in our field, and the difficulties getting indexed in traditional citation databases such as the Thomson ISI Web of Science and the Elsevier SciVerse Scopus. Terry Anderson, the editor of IRRODL, has even spoken of the trouble he has had getting IRRODL listed in these closed databases. It was with interest that I took the opportunity to review The Publish or Perish Book by Anne-Wil Harzing; it is a self-published book that is designed to accompany the use of her Google Scholar citation analysis tool of the same name. As such, the book is structured in a manner to introduce readers to the topic of citation analysis and to orient them to the Publish or Perish tool, providing a detailed guide on how the tool can be used. This is followed by an interesting discussion that is specific to academics on ways in which the tool can be used and to a lesser extent the ways in which citation analysis can be used by different types of individuals in the academy (e.g., faculty up for promotion and tenure, academic administrators) for a variety of purposes (e.g., judging someone's scholarly record or the quality of a journal, making decisions about where to submit an academic paper, assisting in the preparation of a literature review). The book concludes with an examination of the strengths and weaknesses of Google Scholar and the Thomson ISI Web of Science as measures of scholarly rigour in the academy.

The book begins with an introduction to the topic of citation analysis. As a junior faculty member at Wayne State University and a fairly recent graduate of a $\mathrm{PhD}$ program at the University of Georgia, I found that this introduction provided substance to information that I had an awareness of but not a firm understanding. For example, I knew of the Web of Science and had a general understanding of things like impact factors and h-indexes. 
However, over the first 15 pages I felt as if I had taken a short course in all of the different ways in which one's scholarly impact can be measured, the history of each measure, and the strengths and shortcomings of each. As someone with a general understanding of how I could quantify the perceived value of my scholarship, I was quite surprised by how little I actually knew and how much I learned from Harzing's first chapter alone.

The next five chapters provide a very detailed, step-by-step guide to using the Publish or Perish tool. For those unfamiliar with this tool, it is a free PC-based program that interfaces with Google Scholar to conduct citation analysis (although the tool can be used on a Mac by using Bootcamp, Parallels, or Wine and on a Linux-based machine using a Wine compatibility layer), which can be found at http://www.harzing.com/pop.htm . The step-by-step guides provided in these five chapters walk the user through conducting searches based on author name, journal title, specific citation, or multiple citations, along with a number of other general features (e.g., exporting the results, merging duplicate entries, removing selfcitations). These guides are quite well done with images of what the user sees on-screen as well as bolded words or phrases that the user should see or be looking for. Each action that Harzing guides the user through is accompanied by a worked example that she has completed using herself or one of her colleagues. Throughout these five chapters, Harzing regularly outlines some of the limitations that users will experience with the tools, often based on the limitations of Google Scholar itself. However, in conversations with some quantitative faculty members, I get the impression that Harzing underemphasizes some of the limitations of the Google Scholar database (largely through the strategy of pointing out inclusion and geographic limitations in the other databases available for citation analysis). For example, if I count my own journal articles, book chapters, books, conference proceedings, and so on, I have a total of 110 publications as of the end of 2011. While Google Scholar only finds 69 of those publications, it is also true that the Web of Science only includes 4 of those publications and SciVerse Scopus only includes 12 publications. Does that make Google Scholar a more reliable and accurate source for measuring the impact of my scholarship? The impression that Harzing gives the reader is that it is as effective or more effective, which may or may not be the case depending on one's discipline and one's own feelings about the nature of scholarship and the kinds of material included in the Google Scholar database.

Following the chapters that show readers how to use the Publish or Perish tool are six chapters on how specific individuals in the academy might use the tool in their everyday academic endeavours. For example, the first of these six chapters is entitled "Making Your Case for Promotion and Tenure." As a junior faculty member who will be submitting my own promotion and tenure package in the next year, this was a chapter that I read with interest. For example, Harzing makes the suggestion that faculty members getting ready for promotion and tenure should consider comparing their own scholarship with other members of the department at the time they were granted promotion and tenure or with prominent faculty in the field at the time they received their promotion and tenure. Another strategy that Harzing suggests is to compare one's own best papers with the journal average or to compare more recent articles with other articles published in that same year. There is 
also a series of arguments presented that faculty can use in favour of using Google Scholar as a measure in their promotion and tenure package. Harzing also provides this level of suggested use for deans and academic administrators, authors deciding on which journal to submit a manuscript, writers conducting literature reviews, and individuals conducting bibliometric research.

The next two chapters provide a more detailed analysis of the advantages of Google Scholar (approximately 1 page in length), the disadvantages of Google Scholar (approximately 7 pages in length), the advantages of the Thomson ISI Web of Science (approximately 1 page in length), and the disadvantages of the Thomson ISI Web of Science (approximately 17 pages in length). I include the length of coverage of each of these four topics to give you a sense of how much time Harzing invests in her discussion of each database and how my effort appears to highlight the limitations of the Thomson ISI Web of Science. This is understandable given that this book is in support of a tool that uses Google Scholar (a database that has been called into question by many academics, particularly quantitative faculty members). This is not to say that the limitations that Harzing discusses aren't valid or shouldn't be cause for concern. Rather, it is to remind readers of the main purpose of Harzing's book and allow readers of her book to draw their own conclusions.

The final two chapters of the book provide a revised version of a scholarly article that examines the effectiveness of the h-index (and by extension Google Scholar) in the field of marketing that was written by Harzing and a colleague and then an analysis of the number of authors and citations across disciplines in each of the three main citation databases. The book concludes with appendices that provide specific help guidelines for using the Publish or Perish tool.

Overall, this is a book that I would strongly recommend to faculty members who are a part of the promotion and tenure process or who have an interest in their potential scholarly impact. Further, regardless of whether you are a user of the Publish or Perish tool or of how you feel about the Thomson ISI Web of Science and/or Google Scholar, The Publish or Perish Book: Your Guide to Effective and Responsible Citation Analysis is useful for understanding the issue of citation analysis, how it works, and some of the shortcomings of each of the measures.

\section{Athabasca University $\mathbf{I}$}

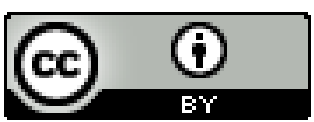

